\title{
ANALISIS PENGELOLAAN PROGRAM PEMBERDAYAAN EKONOMI KELUARGA PERWAKILAN BADAN KEPENDUDUKAN KELUARGA BERENCANA NASIONAL (BKKBN) PROVINSI SUMATERA UTARA TAHUN $2013-2017$
}

\author{
Muhammad Ancha Sitorus \\ BKKBN Perwakilan Provinsi Sumatera Utara \\ *Penulis Korespondensi: anchasitorus@gmail.com
}

\begin{abstract}
Abstrak
Penelitian ini bertujuan untuk mengevaluasi peranan kelompok Usaha Peningkatan Pendapatan Keluarga Sejahtera (UPPKS) dalam pemberdayaan ekonomi keluarga serta peningkatkan keterlibatan keluarga dalam KB. Hal ini diharapkan dapat memberikan kontribusi terhadap penurunan angka kemiskinan sert a penurunan angka Total Fertility Rate (TFR). Metode penelitian yang digunakan adalah metode evaluasi dengan teknik pengumpulan data menggunakan analisis data sekunder kemudian melakukan verifikasi data dengan wawancara kepada pengelola UPPKS di BkkbN Perwakilan Provinsi Sumatera Utara yakni Kepala Kantor Perwakilan BKKBN Sumatera Utara, Kepala Bidang Keluarga Sejahtera dan Kepala Sub Bidang Pemberdayaan Ekonomi Keluarga. Berdasarkan hasil analisis data kelompok UPPKS selama lima tahun terakhir, penganggaran dana untuk pengembangan kelompok mengalami fluktuasi sehingga mempengaruhi kondisi keterlibatan anggota kelompok termasuk keturutsertaan dalam ber-KB. Terdapat 1.667 jumlah kelompok UPPKS dan hanya diikuti oleh 1,95\% keluarga Pra Sejahtera dan Sejahtera I dari total 558.781 keluarga keluarga Pra Sejahtera dan Sejahtera I yang ada di Sumatera Utara. Anggota kelompok UPPKS yang ber KB 1,87\% dari total 558.781 keluarga. Hal ini disebabkan beberapa faktor seperti penurunan anggaran akibat efisiensi oleh pemerintah, penambahan mitra yang membantu pendampingan kelompok UPPKS belum signifikan dan pengurangan akses modal di kelompok yang harus mengembalikan dana modal kelompok ke kas Negara.
\end{abstract}

Kata Kunci: Ekonomi Keluarga, Kelompok UPPKS, Analisis Program

\begin{abstract}
This study aims to evaluate the role Usaha Peningkatan Pendapatan Keluarga Sejahtera (UPPKS) in economic empowerment and capacity building in family planning. This can provide information about reducing poverty and decreasing the total fertility rate (TFR). The research method is evaluate method used secondary data analysis using which was then verified by interviewing the UPPKS organizer in BkkbN Representative of North Sumatra Province, Head of BKKBN North Sumatra Representative Office, Head of the Family Welfare Division and Head of Family Economic Empowerment Sub-Sector. Based on the results of the UPPKS group data analysis over the past five years, budgeting of funds to develop these groups affects the conditions in the KB. There are 1,667 number welfare family I of UPPKS groups and only 1.95\% of families from the total of 558,781 families. Members of the UPPKS group whose family planning is $1.87 \%$ of the total 558,781 families. This is caused by several factors that are very helpful by the government, and partners who help mentoring UPPKS groups have not been significant and access capital in groups that are not yet complete.
\end{abstract}

Keywords: Family Economic, UPPKS Group, Program Analysis

\section{PENDAhuluan}

Dalam pembangunan, kemiskinan menjadi masalah penting yang dihadapi oleh suatu bangsa terutama di negara negara berkembang. Kemiskinan seringkali dipahami sebagai gejala rendahnya tingkat kesejahteraan semata-mata, namun kemiskinan merupakan gejala yang bersifat komplek dan multi dimensi. Ada keterkaitan antar aspek sosial, ekonomi, budaya dan aspek lainnya yang saling mempengaruhi. Pembangunan di Indonesia melalui Rencana
Pembangunan Jangka Menengah (RPJMN) 2015 2019 yang tertuang dalam salah satu poin pembangunan menekankan arah pembangunan Indonesia salah satunya untuk mewujudkan kualitas hidup manusia Indonesia yang tinggi, maju, dan sejahtera. Konsep ini sesuai dengan kesepakatan pembangunan dunia melalui Sustainable Development Goals (SDGs) yang di dukung oleh konsep pembangunan manusia Indonesia (human develop) 
dimana manusia menjadi fokus atau pusat pembangunan.

Berbicara pembangunan manusia, tidak terlepas dari pembangunan program kependudukan. Penduduk merupakan modal dasar dalam pembangunan dengan pengelolaan program kependudukan diatur dalam Undang-Undang RI No. 52 Tahun 2009 tentang Perkembangan Kependudukan dan Pembangunan Keluarga. Dalam rangka peningkatan kesejahteraan keluarga, pasal 48 ayat 1 bagian (f) menyatakan bahwa salah satu cara melakukan kebijakan pembangunan keluarga dalam rangka peningkatan kesejahteraan keluarga adalah dengan meningkatkan peluang dan akses penerimaan sumber daya ekonomi melalui usaha mikro keluarga (BKKBN, 2016). Badan Kependudukan dan Keluarga Berancana nasional (BKKBN) berdasarkan Undang Undang tersebut, merupakan salah satu instansi pemerintah yang menangani masalah kesejahteraan keluarga yang berkaitan dengan peningkatan kualitas kependudukan. Peningkatan kesejahteraan keluarga dikembangkan melalui kelompok Usaha Peningkatan Pendapatan Keluarga Sejahtera (UPPKS) dengan fokus pengembangan usaha mikro yang dilakukan oleh keluarga Indonesia.

Program pemberdayaan ekonomi keluarga melalui kelompok UPPKS merupakan salah satu upaya dalam peningkatan ketahanan dan kesejahteraan keluarga dengan tujuan meningkatkan kemampuan keluarga dalam memenuhi kebutuhan hidupnya. Peningkatan ekonomi keluarga maka keluarga juga diharapkan mampu untuk meningkatkan kondisi pendidikan, kesehatan, pengaturan jumlah serta pembinaan tumbuh kembang anak.

Kelompok UPPKS memberi kesempatan kepada masyarakat, terutama keluarga pra sejahtera dan keluarga sejahtera I (KS 1) untuk meningkatkan kesejahteraan melalui program pemberdayaan ekonomi keluarga. Kegiatan pemberdayaan ekonomi keluarga diberikan melalui pembelajaran pengelolaan usaha keluarga melalui pendekatan pembinaan kelompok kelompok usaha ekonomi produktif dengan harapan peningkatan tahapan kesejahteraan keluarga. Pembinaan pemberdayaan ekonomi keluarga melalui kelompok UPPKS diharapkan mampu meningkatkan kesertaan ber-KB anggota kelompok. Bagi wilayah dengan tingkat kesertaan KB yang masih rendah, kelompok UPPKS diharapkan memiliki daya ungkit terhadap masyarakat untuk meningkatkan kesertaan dalam program KB.

Menurut Parson, et.al dalam buku Edi Suharto, penerapan kebijakan dalam pemberdayaan ekonomi keluarga merupakan salah satu upaya dalam pencapaian target dan tujuan program. Pemberdayaan dalam hal ini adalah sebuah proses dengan mana orang menjadi cukup kuat untuk berpartisipasi dalam, berbagi pengontrolan atas, dan mempengaruhi terhadap, kejadian-kejadian serta lembaga-lembaga yang mempengaruhi

(Suharto, 2014:58).

kehidupannya

Kebijakan merupakan rangkaian konsep dan asas yang menjadi garis besar dan dasar rencana dalam pelaksanaan suatu pekerjaan kepemimpinan dan pemerintahan atau organisasi pernyataan cita cita, tujuan, prinsip atau maksud sebagai pedoman mencapai sasaran (Marbun, 2007). Pada era desentralisasi, masalah pelaksanaan program Kependudukan, KB dan pembangunan keluarga belum menjadi prioritas pembangunan pemerintah kabupaten/kota, dengan alasan program KB tidak langsung memberikan kontribusi bagi pembangunan. Dengan adanya kegiatan Beyond Family Planning salah satunya melalui pemberdayaan ekonomi keluarga melalui kelompok UPPKS, diharapkan mampu memberi kontribusi terhadap peningkatan pemakaian kontrasepsi yang mempunyai dampak terhadap penurunan TFR serta peningkatan tahapan keluarga sejahtera.

Dari beberapa uraian diatas, maka penelitian yang akan dilaksanakan adalah menganalisis pengelolaan program pemberdayaan ekonomi keluarga di Perwakilan BKKBN provinsi Sumatera Utara dalam evaluasi kelompok UPPKS untuk peningkatan tahapan kesejahteraan keluarga dan kesertaan keluarga dalam KB sehingga dapat memberikan kontribusi terhadap penurunan angka kemiskinan serta penurunan TFR.

\section{LANDASAN TEORI}

Usaha Peningkatan Pendapatan Keluarga Sejahtera (UPPKS) adalah kegiatan bersama dalam bentuk pra koperasi yang dilakukan oleh, dari dan untuk kelompok akseptor $\mathrm{KB}$ melalui berbagai kegiatan ekonomi produktif skala mikro/kecil, yang kegiatanya diharapkan dapat menambah/ meningkatkan pendapatan keluarga dan menunjang terwujudnya pelembagaan dan pembudayaan Norma Keluarga Kecil Bahagia dan sejahtera. (NKKBS) di masyarakat, (Pedoman Operasional Pelaksanaan Kegiatan UPPKS). BKKBN (2016:28) mengemukakan evaluasi pelaksanaan kegiatan pemberdayaan keluarga di bidang pengembangan usaha dan peningkatan keterampilan merupakan suatu pengukuran indikator proses dan hasil dari pelaksanaan dukungan sehingga dapat diketahui perkembangan dan keberhasilan baik kualitas maupun kuantitas pelaksanaan kegiatan.

Disamping itu kegiatan pengelolaan pemberdayaan ekonomi keluarga harus dapat menyajikan data dan informasi tentang keberhasilan pencapaian tujuan kegiatan tersebut melalui indikator keberhasilan antara lain:

a. Meningkatnya jumlah kelompok yang beranggotakan keluarga Pra Sejahtera dan KS I, Pasangan Usia Subur (PUS) dari KS II, KS III dan KS III +.

b. Meningkatnya jumlah anggota kelompok yang berusaha dan mempunyai keterampilan untuk meningkatkan produktifitasnya.

c. Bertambah besarnya kebutuhan modal usaha 
disertai dengan lancarnya pengembalian kredit.

d. Meningkatnya jumlah dan mutu produk yang dihasilkan.

e. Makin meluasnya pemasaran hasil produksi sesuai kebutuhan pasar baik lokal maupun luar wilayah.

f. Makin banyaknya anggota kelompok yang bermitra usaha.

g. Makin meningkatnya klasifikasi kelompok dari dasar ke berkembang, dari berkembang ke mandiri dan dari mandiri ke paripurna.

Subarsono menuliskan bahwa suatu kebijakan yang telah direkomendasikan oleh policy maker tidak dapat menjamin kebijakan tersebut dalam implementasinya (Subarsono, 2005: 87). Ada beberapa variable yang mempengaruhi baik individual, kelompok maupun institusi. Implementasi pelaku dan pelaksana melibatkan berbagai upaya pembuat kebijakan untuk mempengaruhi perilaku pelaksana kebijakan agar bersedia member pelayanan dan mengatur kelompok sasaran. Daniel A Mazmanian dan Paul A Sabatier berpendapat terdapat tiga kelompok variable yang mempengaruhi keberhasilan implementasi yaitu karakteristik masalah, karakteristik kebijakan dan lingkungan (Mazmanian dan Sabatier, 1983).

Bridgman \& Davis mengemukakan bahwa pengukuran evaluasi bervariasi sesuai dengan jenis evaluasinya (Tangkilisan, 2003:28). Evaluasi kinerja kebijakan tersebut mengacu pada empat indikator pokok yaitu indikator input, process, outputs dan outcomes. Indikator input memfokuskan pada penilaian apakah sumber daya pendukung dan bahanbahan dasar yang diperlukan untuk melaksanakan kebijakan (uang, SDM, dan sumber daya lainnya. indikator process menfokuskan pada penilaian bagaimana sebuah kebijakan ditransformasikan dalam bentuk pelayanan langsung kepada masyarakat. indikator outputs (hasil), menfokuskan penilaian pada hasil atau produk yang dapat dihasilkan dari sistem atau proses kebijakan publik. terakhir indikator outcomes (dampak), menfokuskan pada pertanyaan dampak yang diterima oleh masyarakat luas atau pihak yang terkena kebijakan.

\section{METODOLOGI PENELITIAN}

Metodologi yang digunakan dalam penelitian ini adalah pendekatan deskriptif dengan melakukan analisis data sekunder yang terdapat di Perwakilan Badan Kependudukan dan Keluarga Berencana Nasional Provinsi Sumatera Utara. Untuk melakukan verifikasi data, dilakukan wawancara dibantu dengan panduan wawancara (interview guide) kepada pengelola UPPKS di BkkbN Perwakilan Provinsi Sumatera Utara yakni Kepala Kantor Perwakilan BKKBN Sumatera Utara, Kepala Bidang Keluarga Sejahtera dan Kepala Sub Bidang Pemberdayaan Ekonomi Keluarga.

\section{ANALISIS DAN PEMBAHASAN}

Pengelolaan program pemberdayaan ekonomi ke luarga yang dalam hal ini adalah pengembangan kelompok UPPKS maka penulis merasa ada beberapa hal yang perlu dievaluasi yaitu meliputi hal-hal seperti dibawah ini:

\subsection{Analisis Input}

Dalam pengelolaan kelompok UPPKS, input utama dalam implementasi kebijakan adalah alokasi sumber daya baik sumberdaya manusia maupun alokasi penganggaran dana yang dianggarkan untuk mencapai target kinerja program pemberdayaan ekonomi keluarga. input pengalokasian penganggaran program pemberdayaan ekonimi keluarga dapat kita lihat dari grafik di bawah ini.

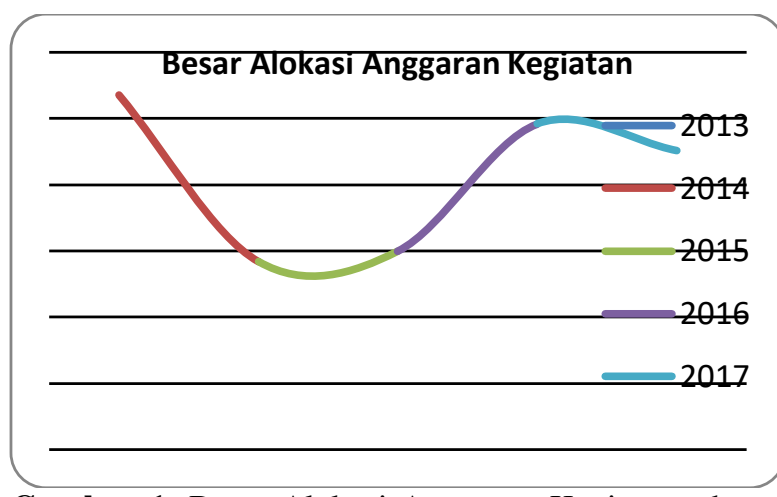

Gambar 1. Besar Alokasi Anggaran Kegiatan tahun 2013-2017 (Sumber Data : Diolah dari RKA-KL Perw. BKKBN SU

Dari data diatas dapat kita lihat bahwa ada penurunan volume kegiatan dalam pengelolaan program pemberdayaan ekonomi keluarga pada tahun 2014 dan mulai mengalami kenaikan kembali mulai tahun 2015 sampai 2017. Penurunan anggaran pada kegiatan pemberdayaan ekonomi keluarga sejak 2014 diakibatkan oleh efisiensi anggaran kementrian/lembaga yang dilakukan secara nasional.

Sumber daya selain alokasi anggaran adalah SDM yang mengelola program. Untuk pengelolaan program pemberdayaan ekonomi keluarga ditangani dalam bidang keluarga sejahtera dan pemberdayaan keluarga (KS/PK) dengan sub bidang tersendiri yang dijalankan oleh kepala sub bidang dibantu oleh $1 \mathrm{~s} / \mathrm{d} 2$ orang staf. Untuk mencapai tujuan dari program pemberdayaan ekonomi keluarga, peran mitra dalam memberhasilkan program juga dianggap strategis sebagai salah satu sumberdaya yang ikut dalam pengembangan program. Kemitraan secara konseptual dapat diartikan sebagai kerjasama antar usaha kecil, menengah, atau besar disertai pembinaan dan pengembangan berkelanjutan oleh usaha dengan memperhatikan prinsip saling memerlukan, memperkuat dan menguntungkan (Soemardjo, 2004)

Kemitraan yang dibangun pada 2013 dilakukan Memorandum of Understanding (MoU) antara Perwakilan BKKBN Sumut dengan Lembaga Penegabdian Masyarakat (LPM) Universitas Negeri 
Medan dan PT. Telkom Persero, Tbk untuk pembinaan dan peningkatan kapasitas pengelola program kabupaten/ kota sampai kelompok UPPKS. modal dilakukan bekerjasama dengan Bank Sumut dengan pengintegrasian pada program kredit sumut sejahtera yang fokus pada pengembangan dan pembinaan kelompok ekonomi mikro seperti UPPKS. Pada tahun 207 masih di jajaki kemitraan dengan Perkebunan Nusantara (PTPN) IV untuk pengembangan kelompok UPPKS.

\subsection{Analisis Proses}

Proses pengembangan program pemberdayaan ekonomi keluarga mengacu pada renstra BKKBN yang tertuang pada RPJMN 2015 - 2019. Program yang ditetapkan mengacu pada kebijakan yang ditetapkan bersama pada level nasional melalui kedeputian KS/PK melalui Direktorat Pemberdayaan Ekonomi BKKBN. Kebijakan nasional dipecah pada target yang menjadi kontrak kinerja provinsi yang akan dicapai pada tahun berjalan yang ditetapkan sebelumnya pada Rapat Kerja Nasional (Rakernas). Hasil rakernas diteruskan di level provinsi melalui rapat Kerja Daerah (Rakerda) kepada Kabupaten/ Kota dengan pembagian Kontrak Kinerja Kabupaten/ Kota yang mengacu dari hasil Rakernas.

Organisasi Perangkat Daerah (OPD) - KB Kabupaten/ Kota selanjutnya akan menyusun strategi sampai level desa untuk mencapai target kinerja program Pemberdayaan ekonomi keluarga. Berdasarkan besaran kegiatan yang dilakukan oleh pengelola program level provinsi, maka dari pelaksanaan kegiatan berjalan dapat kita kelompokkan dalam volume kegiatan peningkatan pemberdayaan sebagai berikut.

Tabel 1. Alokasi Kegiatan Program Pemberdayaan Ekonomi Keluarga

\begin{tabular}{|c|c|c|c|c|c|}
\hline \multirow[b]{2}{*}{ KEGIATAN } & \multirow[b]{2}{*}{2013} & \multirow[b]{2}{*}{2014} & \multicolumn{3}{|c|}{201} \\
\hline & & & 2015 & 6 & 2017 \\
\hline Pengembangan & & & & & \\
\hline Wirausaha & 3 & 5 & 4 & 3 & 2 \\
\hline Penyediaan & & & & & \\
\hline Fasilitas Modal & 0 & 0 & 1 & 1 & 1 \\
\hline Pengembangan & & & & & \\
\hline Jejaring & 3 & 5 & 4 & 2 & 1 \\
\hline Pengembangan & & & & & \\
\hline $\begin{array}{l}\text { Keterampilan } \\
\text { Teknis dan } \\
\text { manajerial }\end{array}$ & 2 & 1 & 2 & 2 & 2 \\
\hline
\end{tabular}

\section{Sumber Data : Diolah dari RKA - KL Perw. BKKBN SU}

Dari data diatas, dapat kita lihat bahwa program fasilitasi dan penyediaana fasilitas modal untuk kelompok UPPKS masih sangat minim. Modal dalam hal ini termasuk modal uang dan alat produksi seperti alat teknologi tepat guna (ATTG) yang mendukung pengembangan kelompok UPPKS yang bisa meningkatkan tahapan kelompok dari tingkat dasar menjadi mandiri. Program kegiatan sebagian besar terfokus pada pengembangan wirausaha melalui kegiatan dukungan pembinaan, pendampingan kelompok UPPKS dan penilaian lomba UPPKS unggulan. Program pengembangan jejaring dilakukan melalui sosialisasi program, FGD, pameran dan gelar dagang serta workshop dengan mitra kerja. Pengembangan teknis dan manajerial juga dalam kurun waktu lima tahun terakhir ini masih minim hanya sebatas kegiatan orientasi dan pengembangan kapasitas.

Peran mitra dalam program pemberdayaan ekonomi keluarga juga bisa menjadi salah satu upaya strategis dalam mencapai tujuan program. Pada tahun 2013 LPM Unimed dan BKKBN Sumut telah melakukan pendampingan 79 kelompok melalui pendanaan IbM dan IbK Diretorat Penelitain dan Pengabdian Masyarakat Ditjen Dikti Kemendikbud. Pada 2014, dilakukan juga 42 kegiatan pembinaan kelompok UPPKS dan pembiayaan kegiatan 20 kelompok UPPKS melalui skema pendanaan Bantuan Operasional Perguruan Tinggi Negeri (BOPTN). Peningkatan layanan kelompok UPPKS ini diharapkan dapat mempercepat peningkatan pendapatan keluarga yang akan meningkatkan tahapan kesejahteraan dan kesertaan ber KB keluarga.

Dengan UU no. 23, pengelolaan program KKBPK menjadi tanggung jawab Pemerintah daerah dengan program pemberdayaan ekonomi keluarga sebagai bagian dari program strategis. Selanjutnya akan diterbitkan NSPK program pemberdayaan ekonomi keluarga sebagai salah satu upaya pengembangan program di Kabupaten/ Kota.

\subsection{Analisis Output}

Output dari pengelolaan program UPPKS adalah meningkatnya jumlah kelompok, keluarga Pra Sejahtera (Pra S) dan Keluarga Sejahtera I (KS I) dan kesertaan ber KB Pasangan Usia Subur (PUS) dalam kelompok UPPKS. Output pengelolaan kelompok UPPKS dalam kurun waktu tiga tahun terakhir dapat dilihat melalui tabel berikut:

Tabel. 2 Capaian Target Program pemberdayaan Ekonomi Keluarga

\begin{tabular}{|c|c|c|c|c|c|c|}
\hline$\underset{⿱ 乛}{Z}$ & 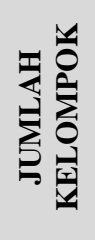 & 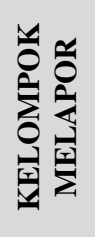 & 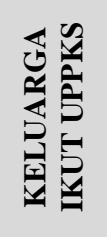 & 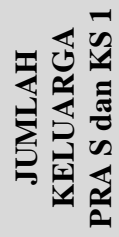 & 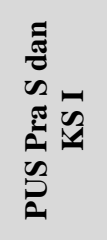 & 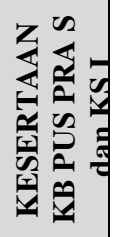 \\
\hline 2015 & 1.560 & 1.391 & 24.042 & 14.430 & 10.505 & 8.299 \\
\hline 2016 & 1.567 & 1.484 & 25.097 & 15.478 & 10.812 & 8.440 \\
\hline 2017 & 1.667 & 1.407 & 21.409 & 13.074 & 9.126 & 7.071 \\
\hline
\end{tabular}

Sumber Data : Diolah dari Statistik Rutin BKKBN

Dari Tabel diatas, kita bisa lihat dalam tiga tahun terakhir terjadi peningkatan dalam pembentukan kelompok UPPKS di masyarakat.. Persentase keluarga Pra $\mathrm{S}$ dan KS 1 ikut UPPKS sebesar $60 \%$ dari total keluarga ikut UPPKS dan $70 \%$ keluarga adalah PUS 
dengan persentase kesertaan ber $\mathrm{KB}$ sebanyak $80 \%$. Dalam kurun waktu 2016 ke 2017 terjadi penurunan dalam kuantitas laporan maupun keluarga yang aktif pada kegiatan kelompok UPPKS.

Penurunan kegiatan di tahun 2017 diakibatkan oleh kendala di lini lapangan dengan pengembalian dana bansos yang bersumber dari dana APBN yang ada di kelompok UPPKS. Dana di kelompok yang harus dikembalikan ke kas Negara sebesar Rp. 667.439.000,dan sampai saat ini yang sudah dikembalikan ke kas Negara sejumlah Rp. 110.469.000,-. Besaran anggaran di kelompok sebesar Rp. 5.000.000,- sebagai modal dalam proses produksi. Pengembalian modal ini menjadi penghambat pengembangan kelompok UPPKS. Penurunan ini diharapkan agar menjadi perhatian bersama dalam penguatan kembali program pemberdayaan ekonomi keluarga di lini lapangan.

\subsection{Analisis Outcome}

Jumlah keluarga Pra S dan KS I di Provinsi Sumatera Utara melalui publikasi Sumatera Utara dalam Angka BPS adalah 795.088 keluarga atau $26.79 \%$ dari total keluarga yang ada di Sumatera Utara (2.967.486 keluarga). Jumlah keluarga tahapan Pra S dan KS I masih sangat besar, dan ini menjadi perhatian semua pihak dalam menekan angka ini. Dari total keluarga Pra S dan KS I, keluarga yang ikut UPPKS masih masih menjaring kurang dari $1.95 \%$ dari total keluarga Pra S dan KS I di Sumatera Utara.

Jumlah pasangan usia subur di Provinsi Sumatera Utara berdasarkan laporan statistik rutin BKKBN adalah 1.874.852 keluarga dan PUS keluarga Pra S dan KS I sebanyak 558.781 keluarga (29.8\%). Jumlah kesertaan ber KB PUS anggota kelompok UPPKS Pra S dan KS I kurang dari $1,5 \%$. Dari data diatas menunjukkan program pemberdayaan ekonomi keluarga masih belum maksimal dalam menaikkan partisipasi dan tahapan keluarga Pra S dan KS I dalam kelompok UPPKS. Begitu juga partisipasi dalam program KB untuk menekan kelahiran keluarga Pra S dan KS I masih belum memberikan hasil yang maksimal menekan angka kelahiran. Sehingga perlu ada upaya revitalisasi pengelolaan program untuk mencapai tujuan dalam pengembangan program KKBPK.

\section{KESIMPULAN DAN SARAN}

Berdasarkan hasil penelitian yang dilakukan, maka dapat disimpulkan sebagai berikut:

a. Dari evaluasi pengelolaan program pemberdayaan ekonomi keluarga melalui kelompok UPPKS, selama lima tahun terakhir mengalami fluktuasi. Jumlah kelompok sebanyak 1.667 dengan Partisipasi Keluarga Pra Sejahtera dan Sejahtera I hanya sekitar $1,95 \%$ dari total 558.781 keluarga di Sumatera Utara. Begitu juga partisipasi dalam program $\mathrm{KB}$, anggota kelompok UPPKS yang ber KB 1,87\% dari total 558.781 keluarga. Hal ini disebabkan beberapa faktor, dalam kurun waktu 5 tahun terakhir terdapat penurunan anggaran akibat efisiensi oleh pemerintah. Mitra yang membantu pendampingan kelompok UPPKS masih belum ada penambahan signifikan, begitu juga pengurangan akses modal di kelompok yang harus mengembalikan dana modal kelompok ke kas Negara menyebabkan aktifitas kelompok mengalami penurunan.

b. Kebijakan terkait program pemberdayaan ekonomi keluarga dalam lima tahun terakhir juga masih belum mampu memunculkan strategi yang efektif dalam peningkatan aktifitas kelompok di lini lapangan. Kegiatan dalam program sebagian besar masih fokus pada pengembangan wirausaha di kalangan kelompok dan keluarga sasaran. Diperlukan peran Mitra kerja sebagai salah satu patner strategis dalam pembinaan dan pendampingan kelompok UPPKS yang mendorong aktivitas dan penambahan akses modal pada program Pemberdayaan Ekonomi Keluarga.

Saran yang dapat diberikan dari kesimpulan diatas adalah:

a. Dalam pengembangan program pemberdayaan ekonomi keluarga diperlukan revitalisasi kebijakan dan strategi baru agar dengan proses perencanaan anggaran maupuin sumber daya pengelola yang lebih baik agar bisa meningkatkan kesertaan mitra kerja maupun modal kelompok.

b. Aktivitas kelompok di lapangan perlu terus dibina dan didampingi lebih intens melalui penyuluh KKBPK dan mitra kerja agar peningkatan keluarga Pra S dan KS I di kelompok dapat terealisasi serta meningkatkan kesertaan ber-KB di wilayah tersebut.

c. Perlu adanya peningkatan kerjasama dengan Bank, Perusahaan, Perguruan Tinggi, Koperasi agar bisa meningkatkan akses modal dan pendampingan ke kelompok sasaran yang mampu mempengaruhi aktivitas dan produksi dalam kelompok UPPKS.

d. Diharapkan dapat lebih ditingkatkan lagi pelatihan dan sosialisasi program baik kepada mitra, kader, penyuluh KKBPK, dan anggota kelompok UPPKS sebagai salah satu upaya peningkatan kompetensi pengelolaan kelompok dilapangan.

\section{DAFTAR PUSTAKA}

BKKBN. 2013. Buku Pedoman Pembinaan dan Pengembangan Ekonomi Keluarga melalui Kelompok UPPKS, Jakarta: Direktorat Pemberdayaan Ekonomi Keluarga Badan Keluarga Berencana Nasional.

BPS. 2016. Sumatera Utara dalam Angka. Medan: BPS

Hardiyanto, 2009. Pengelolaan Usaha Kelompok, Jakarta : Direktorat Pemberdayaan Ekonomi Keluarga Badan Keluarga Berencana Nasional.

Marbun. (2007). Kamus Politik. Jakarta: Pustaka Sinar Harapan.

Mazmanian, Daniel A dan Sabatier, Paul A. 1983. Implementation and Public. Policy. New 
York: HarperCollins

Simatupang, Zulkifli. 2014. Kemitraan Membangun Ketahanan dan Kesejahteraan Keluarga. Medan: Unimed Press.

Soemardjo, et all. 2004. Teori dan Praktek Kemitraan Bisnis. Jakarta: Penebar Swadaya

Subarsono, A. G. 2005. Analisis Kebijakan Publik Konsep, Teori dan Aplikasi. Yogyakarta : Pustaka Pelajar

Suharto, Edi. 2014. Membangun Masyarakat Memberdayakan Rakyat. Bandung: PT. Adi Tama

Tangkilisan, Hessel Nogi S. 2003. Kebijakan Publik yang Membumi: Konsep, Strategi dan Kasus, Yogyakarta: Lukman Offset 